\title{
Identification of Polyphenolic Compounds and Black Tea Extract as Potent Inhibitors of Lipid Membrane Destabilization by $\mathrm{A} \beta_{42}$ Aggregates
}

\author{
Alison J. Gauci ${ }^{\mathrm{a}}$, Mario Caruana ${ }^{\mathrm{a}}$, Armin Giese ${ }^{\mathrm{b}}$, Charles Scerri ${ }^{\mathrm{c}}$ and Neville Vassallo ${ }^{\mathrm{a}, *}$ \\ ${ }^{a}$ Department of Physiology \& Biochemistry, University of Malta, Msida, Malta \\ ${ }^{\mathrm{b}}$ Zentrum für Neuropathologie und Prionforschung, Ludwig-Maximilians-Universität, München, Germany \\ ${ }^{\mathrm{c}}$ Department of Pathology, University of Malta, Msida, Malta
}

Handling Associate Editor: Othman Ghribi

Accepted 25 July 2011

\begin{abstract}
Amyloid- $\beta(A \beta)$ aggregation is a recognized key process in the pathogenesis of Alzheimer's disease (AD). Misfolded $\mathrm{A} \beta$ peptides self-assemble into higher-order oligomers that compromise membrane integrity, leading to synaptic degeneration and neuronal cell death. The main aim of this study was to explore whether small-molecule compounds and black tea extract can protect phospholipid membranes from disruption by $\mathrm{A} \beta$ aggregates. We first established a robust protocol for aggregating $\mathrm{A} \beta_{42}$ peptides into a range of oligomers that efficiently permeabilized small unilamellar liposomes. Next, 15 natural plant polyphenolic compounds, $8 \mathrm{~N}^{\prime}$-benzylidene-benzohydrazide (NBB) compounds and black tea extract were assessed for their ability to antagonize liposome permeabilization by the $A \beta_{42}$ oligomers. Our data indicates that black tea extract, the flavones apigenin and baicalein, and the stilbene nordihydroguaiaretic acid (NDGA) are indeed potent inhibitors. Taking into consideration the results of all the small-molecule polyphenols and NBB compounds, it can be proposed that a dihydroxyphenyl ring structure, alone or as part of a flavone scaffold, is particularly effective for protection against membrane damage by the $\mathrm{A} \beta_{42}$ oligomers. Given the critical role of membrane perforation in the neurodegenerative cascade, these conclusions may guide the design and development of novel therapeutic drugs in AD.
\end{abstract}

Keywords: Alzheimer's disease, amyloid- $\beta$, black tea, liposomes, $N^{\prime}$-benzylidene-benzohydrazide, oligomers, polyphenols

\section{INTRODUCTION}

Alzheimer's disease (AD) is a major economical and social burden in the Western world, being the most common cause of dementia in all age groups and the fourth common cause of death following cardiovascular disease, cancer, and stroke [1]. Clinical

\footnotetext{
*Correspondence to: Dr. Neville Vassallo MD, Ph.D., Department of Physiology and Biochemistry, University of Malta,TalQroqq, Msida MSD 2080, Malta. Tel.: 35621 323660; Fax: 356 21 310577; E-mail: neville.vassallo@um.edu.mt.
}

manifestations include a worsening cognitive deficit, initially limited to memory alone, but which ultimately interferes with normal social and occupational functioning [2]. Neurodegeneration in $\mathrm{AD}$ is relentless and irreversible, and an effective disease-modifying therapy still remains to be developed.

Nevertheless, great strides have been made in trying to understand the cellular and molecular mechanisms that induce $\mathrm{AD}$ [3]. In particular, a formidable body of evidence gathered from genetic, biochemical, and transgenic mouse studies, supports the so-called 
'amyloid-beta' $(\mathrm{A} \beta)$ hypothesis [4]. Essentially, the hypothesis centers on the pathological aggregation and accumulation in the brain of higher-order multimeric structures derived from monomeric $\mathrm{A} \beta$ peptides. The former are represented by small soluble oligomers, larger protofibrils, and insoluble amyloid fibrils [5] that form extracellular plaque deposits, one of the major pathological hallmarks found in specific regions of postmortem AD brains [6]. Mutations associated with increased propensity of $A \beta_{42}$ peptide to form protofibrils correlated nicely with neuronal dysfunction and degeneration in a Drosophila model of AD, thus lending strong support to the view that $A \beta_{42}$ aggregation is a critical factor driving neuronal dysfunction in $\mathrm{AD}$ [7]. Moreover, accumulating evidence indicates that neurodegeneration and memory loss is actually triggered by the highly toxic soluble oligomeric species of $A \beta$ [8-11]. Indeed, levels of soluble $A \beta$ oligomers correlate well with dementia and AD severity [12-14].

The possible mechanisms underlying the neurotoxic actions of $A \beta$ oligomers are under intense investigation: interaction with membranes, of both cells and organelles, appears to be a critical first step in the pathway to toxicity [15]. Numerous works have demonstrated that $A \beta$ disturbs properties of artificial and isolated biological membranes, and of plasma membranes in living cells [16-19]. Specifically, $A \beta$ oligomers can incorporate into neuronal membranes to form calcium-permeable channels or pores $[20,21]$. The resultant excessive increase in intracellular calcium then sets off a cascade of deleterious sequelae culminating in synaptic degeneration and apoptosis [22-24]. In line with the concept that $\mathrm{A} \beta$-induced membrane perforation is a fundamental mechanism, reduction in ability of $A \beta$ oligomers to bind lipid membranes was associated with decreased toxicity to neuronal cells $[25,26]$. Also, smallmolecule and peptide blockers of $A \beta$ calcium channels potently protected neurons from cytotoxicity [27, 28]. Notwithstanding this significant body of evidence, a demonstration that membrane perforation and/or destabilization genuinely occur in vivo, resulting in synaptotoxicity and neuronal cell death, is still lacking.

Several types of low-molecular-weight chemical compounds have been previously shown to inhibit $\mathrm{A} \beta$ oligomer formation in vitro [29-33]. Of these, polyphenols are an important class of beneficial naturally-occurring molecules that are common constituents in human diet and medicinal plants [34]. In most cases, foods contain complex mixtures of polyphenols, which are often poorly characterized. Fruit, tea, and red wine represent the main sources, with daily intake averaging $1 \mathrm{~g} /$ day [35]. Polyphenols essentially have several hydroxyl groups on aromatic rings, thereby explaining their high antioxidant activity [36]. In recent years, much attention has been paid to the interaction between polyphenols and cellular membranes, since it has been shown that they can interact with and permeate lipid bilayers [37]. Some studies have proposed that polyphenol molecules interact only with the outer leaflet of bilayers [38], whilst others report penetration of the lipid membrane by intercalation of polyphenols between flexible acyl chains of the phospholipids [39]. In particular, a rigidifying effect on the bilayer consequently hindering permeabilization by an $A \beta$ peptide, has been described [40].

Therefore, the anti-A $\beta$ aggregation effects of polyphenols on the one hand, together with their capacity to protect lipid membranes on the other, make them attractive candidate molecules in AD therapy. As a matter of fact, several recent studies involving dietary supplementation with polyphenolic compounds have consistently shown improvement in cognitive function and AD pathology in transgenic mice [41-45]. Again, recent epidemiological studies suggest that tea, one of the most highly consumed polyphenolic beverages in the world, might be a useful agent in the prevention or treatment of AD/dementia [46-48].

In this study, a fluorescence-based vesicle permeabilization assay was first established and characterized. Next, the assay was used as a platform to screen a group of low-molecular-weight compounds, as well as black tea extract, for their ability to antagonize liposome permeabilization by $A \beta_{42}$ peptide aggregates. Two different classes of small molecules were chosen, a group of 15 naturally-occurring polyphenols and another group of 8 synthetic $\mathrm{N}^{\prime}$-benzylidene-benzohydrazide (NBB) derivatives. Black tea extract provided a rich and complex milieu of bioactive polyphenols. Our conclusions enabled us to gain insight into particularly important structure-activity relationships which may have implications for development of diseasemodifying therapy in AD.

\section{MATERIALS AND METHODS}

\section{Materials}

Purified synthetic $A \beta_{42}$ was purchased from rPeptide (Bogart, GA, USA); phospholipids were purchased as a synthetic blend in chloroform: 1,2dioleoyl-sn-glycero-3-phosphoethanolamine (DOPE)/ 1,2-dioleoyl-sn-glycero-3-phosphoglycerol (DOPS)/ 1,2-dioleoyl-snglycero-3-phosphocholine (DOPC) in 
a molar ratio of $5: 3: 2$, from Avanti Polar Lipids (Alabaster, AL, USA); Oregon Green ${ }^{\circledR} 488$ BAPTA-1 (OG) was purchased from Invitrogen (Darmstadt, Germany); M-PER ${ }^{\circledR}$ was obtained from Pierce (Rockford, USA); apigenin (Api), baicalein (Baic), black tea extract (BTE; >80\% theaflavins), catechin (Cat), (-)-epigallocatechin gallate (EGCG), fisetin (Fis), fluorescein isothiocyanate conjugated to dextran (FITC-dextran $40 \mathrm{kDa}$, FITC-dextran $70 \mathrm{kDa}$ ), genistein (Gen), ginkgolide B (Gink), ionomycin, morin (Mor), myricetin (Myr), nordihydroguaiaretic acid (NDGA), purpurogallin trimethyl ether (Purp), quercetin (Quer), rosmarinic acid (Rosm), resveratrol (Resv), thioflavin T (ThT) were all purchased from Sigma-Aldrich (Munich, Germany); scutellarein (Scut) was obtained from Pharmasciences Laboratories (Cour-bevoie, France); N'-benzylidenebenzohydrazide (NBB) compounds were obtained from Chembridge Corp. (San Diego, CA, USA). In all cases, the purity of the compounds was $>98 \%$. Polyphenols, NBB compounds and BTE were prepared as stock solutions in DMSO and stored at $-20^{\circ} \mathrm{C}$. During the experiments, compounds were kept away from light and used immediately after thawing.

\section{Preparation of $A \beta_{42}$ aggregates}

Lyophilized $\mathrm{A} \beta_{42}$ was dissolved in $10 \mathrm{mM} \mathrm{NaOH}$ to $200 \mathrm{mM}$, and stored at $-80^{\circ} \mathrm{C}$. The aggregation protocol was based on that of Necula et al. [49], which generates $\mathrm{A} \beta$ oligomers and protofibrils. Thus, oligomerization was achieved by incubating $45 \mu \mathrm{M}$ $\mathrm{A} \beta_{42}$ in sterile PBS (pH 7.4) for $2 \mathrm{~h}$ at $37^{\circ} \mathrm{C}$. To minimize evaporation, microfuge tubes $(1.5 \mathrm{ml}$; Eppendorf, Germany) were sealed with Whatman ${ }^{\circledR}$ adhesive film.

\section{Thioflavin T fluorescence assay}

Thioflavin $\mathrm{T}$ (ThT) is a dye widely used for the detection of cross- $\beta$-sheet structures in proteins, characteristic of the amyloid fibrillar form. The ThT assay was modified from El-Agnaf et al. [50]. Aggregation of $\mathrm{A} \beta_{42}$ was monitored over $24 \mathrm{~h}$; at each sampling time, a $10 \mu \mathrm{l}$ aliquot of the $\mathrm{A} \beta_{42}$ solution was diluted in $190 \mu \mathrm{l}$ PBS (pH 7.5) containing $12 \mu \mathrm{M}$ ThT. Fluorescence was measured in black 96-well plates using an FLx800TBID microtiter plate reader (BioTek, Germany), with excitation at $440 \mathrm{~nm}$ and emission at $490 \mathrm{~nm}$. To allow for background fluorescence, the fluorescence intensity of a blank PBS solution was subtracted from all readings. Data were measured in triplicates and averaged for evaluations.
Analysis of $A \beta_{42}$ aggregation by immunoblotting

Immunoblotting of $A \beta_{42}$ aggregation samples was performed using precast NuPAGE ${ }^{\circledR}$ Novex $4-12 \%$ BisTris gels (Invitrogen, Darmstadt, Germany) according to the manufacturer's instructions. The samples were prepared in NuPAGE ${ }^{\circledR}$ gel-loading buffer and resolved by subjecting to electrophoresis in $1 \times$ MOPS SDS buffer at $150 \mathrm{~V}$ for $\sim 1.5 \mathrm{~h}$. Samples were not boiled to avoid any oligomer dissociation. Transfer to nitrocellulose membrane (Hybond-ECL; General Electric, USA) was carried out using XCell IITM Blot Module (Invitrogen, Darmstadt, Germany), at $30 \mathrm{~V}$ for $1 \mathrm{~h}$. After transfer, the membrane was immersed in $5 \%$ blocking reagent and left overnight at $4^{\circ} \mathrm{C}$. $\mathrm{A} \beta$ was detected using $6 \mathrm{E} 10$ monoclonal antibody ( $1: 4000$; Covance, Princeton, NJ, USA). Sites of primary antibody binding were detected with horseradish peroxidase-conjugated secondary antibody $(1: 8000)$ and blots were developed using ECLplus kit (General Electric, USA) according to the manufacturer's instructions.

\section{Preparation of Small Unilamellar Vesicles (SUVs)}

All vesicles used in our study were made up of the phospholipids DOPE:DOPS:DOPC $(5: 3: 2)$. These vesicles have a net negative charge and lipid moieties native to the neuronal environment [51]. Typically, $50 \mu \mathrm{g}$ of lipids was thoroughly dried from a chloroform solution under vacuum, to yield a thin lipid film at the bottom of a glass vial. The thin film was hydrated by adding $500 \mu \mathrm{l}$ of a solution, $100 \mathrm{mM} \mathrm{KCl}$, $10 \mathrm{mM}$ MOPS/Tris, $1 \mathrm{mM}$ EDTA (pH 7.0), containing $50 \mu \mathrm{M}$ OG dye. The suspension was left to hydrate for $60 \mathrm{~min}$, with vortexing approximately every $15 \mathrm{~min}$ until it turned very cloudy. Subsequently, 0.8 M Mega9 detergent was added to the suspension, and it was vortexed gently until it appeared clear again. The lipidsolution was then carefully loaded into Spectra/Por ${ }^{\circledR}$ (Spectrum Labs, Breda, The Netherlands) membrane tubing (pore size, $3.5 \mathrm{kDa}$ ) and subjected to dialysis for $6 \mathrm{~h}$ at room temperature against a buffer (5l) containing $100 \mathrm{mM} \mathrm{KCl}, 10 \mathrm{mM}$ MOPS/Tris (pH 7.0). This was followed by two successive overnight dialyses at $4^{\circ} \mathrm{C}$ in the dark, with renewal of fresh buffer each time. Liposomes were retrieved from the tubing and kept at $4^{\circ} \mathrm{C}$ covered in aluminum foil.

A similar protocol was used to prepare FITCdextran loaded liposomes, but in this case the lipid film was resuspended in $500 \mu \mathrm{l}$ of $2 \mathrm{mg} / \mathrm{ml}$ FITC-dextran $(40 \mathrm{kDa} ; 70 \mathrm{kDa})$ whilst the untrapped FITC-dextran 
molecules were removed by 3-4 cycles of centrifugation $(22,000 \mathrm{~g}$ for $30 \mathrm{~min})$. The size and uniformity of the vesicle population were checked using a Zetasizer Nano S dynamic light scattering (DLS) device (Malvern, Worcestershire, UK). The vesicles were relatively uniformly-sized with an average diameter of $67 \pm 14 \mathrm{~nm}$ (data not shown), and hence categorized as SUVs.

\section{Liposome permeabilization assays}

Liposome permeabilization assays indicate disruption of lipid vesicle membrane by release of an encapsulated fluorophore [52]; in these experiments, the calcium-sensitive fluorophore Oregon Green and FITC-dextran molecules were used. In the case of OG, increased fluorescence resulting from inward calcium leakage and/or outward dye leakage indicates permeabilization of the liposomal membrane. In the case of FITC-dextran, FITC-dextran molecules entrapped in the liposomes are at high concentration and therefore self-quenching occurs; hence, leakage can be monitored as a relief of quenching. Fluorescence measurements were carried out using a microplate reader (FLx800-TBID; BioTek, Germany) set with excitation and emission wavelengths appropriate for the fluorophore being used (for OG: excitation $=485 \mathrm{~nm}$, emission $=528 \mathrm{~nm}$; for FITC: excitation $=495 \mathrm{~nm}$, emission $=520 \mathrm{~nm}$ ). Readings were taken in black 96well microtiter plates $(100 \mu$ l total well volume $)$ at a constant temperature of $22^{\circ} \mathrm{C}$. For kinetic readings, the reader was programmed to take measurements at regular intervals, typically for 15-20 min. Before each reading, shaking for $30 \mathrm{~s}$ ensured adequate mixing of the samples. Fluorescence intensity data was acquired using KC Junior ${ }^{\mathrm{TM}}$ software (BioTek, Germany).

Aggregated $\mathrm{A} \beta_{42}$ was added to $25 \mu \mathrm{M}$ liposomes in assay buffer $(1 \mathrm{mM} \mathrm{CaCl} 2,100 \mathrm{mM} \mathrm{KCl}, 10 \mathrm{mM}$ MOPS/Tris, $1 \mathrm{mM}$ EDTA, pH 7.0). The apparent percentage permeabilization value was calculated according to the equation:

Permeabilization $(\%)=100 \times\left(F-F_{0}\right) /\left(F_{\max }-F_{0}\right)$,

where $F$ denotes the maximum fluorescence intensity of the measured sample; $F_{\max }$ denotes the maximum fluorescence intensity after the addition of $2 \mu \mathrm{M}$ ionomycin (a calcium ionophore) in the case of OG liposomes, or after the addition of 5\% M-PER ${ }^{\circledR}$ (a membrane detergent) in the case of FITC-dextran liposomes; and $\mathrm{F}_{0}$ represents the fluorescence of intact vesicles. Fluorescence intensity values are given in RFU.

\section{Assays for inhibition of $A \beta_{42}$-induced liposome permeabilization}

$1 \mu \mathrm{M}$ aggregated $\mathrm{A} \beta_{42}$ was incubated for $10 \mathrm{~min}$ with compounds in assay buffer, prior to the addition of $25 \mu \mathrm{M}$ liposomes. Disruption of lipid vesicles by $\mathrm{A} \beta$ in the presence of compound was calculated as a percentage of permeabilization caused by $\mathrm{A} \beta$ alone (theoretical maximum, 100\%). Tested compounds included: (i) 15 natural plant polyphenols (typically at $50 \mu \mathrm{M}$ ): Api, Baic, Cat, EGCG, Fis, Gen, Gink, Mor, Myr, NDGA, Purp, Quer, Rosm, Resv and Scut; (ii) BTE (typically at $15 \mu \mathrm{g} / \mathrm{ml}$ ); (iii) $8 \mathrm{NBB}$ derivatives (typically at $10 \mu \mathrm{M}$ ). At these typical concentrations none of the compounds had any significant destabilizing effect on the liposomal membranes. Autofluorescence (where necessary) was measured for each compound and was subtracted from the sample well values.

\section{Statistical analysis}

Statistical analyses were performed using GraphPad Prism 5 software (GraphPad Software, Inc.). Results were expressed as the means and the standard error of the mean (SEM) values, with $n$ as the number of experiments. Differences between means were determined by unpaired Student's $t$ test. In all analyses, the null hypothesis was rejected at the 0.05 level.

\section{RESULTS}

\section{Characterization of $A \beta_{42}$ aggregates}

In a working hypothesis of $\mathrm{AD}, \mathrm{A} \beta$ aggregates (typically, oligomers) directly damage neuronal and synaptic membranes, leading to ionic dyshomeostasis and eventually neurodegeneration. We therefore wanted to generate $A \beta_{42}$ multimeric species, mainly oligomers, that robustly compromised membrane permeability of SUVs. The latter vesicles are a representative model of native brain neuronal membranes, having a net negative charge and similar phospholipid composition.

The kinetics of $A \beta$ aggregation were first monitored by measuring ThT fluorescence [53]. As expected, there was a lag phase (with no change in cross- $\beta$-sheet structure) during the first $2 \mathrm{~h}$ of incubation, followed by a 4-h growth phase during which $A \beta_{42}$ peptides aggregated into an increasingly fibrillar structure (Fig. 1A). Such fibrillization kinetics are consistent with a nucleated polymerization mechanism and hence 




Fig. 1. Characterization of amyloid- $\beta$ aggregate species. A) Aggregation kinetics of $A \beta_{42}$ peptide (45 $\left.\mu \mathrm{M}\right)$ in $\mathrm{PBS}$, pH 7.4, was monitored at $37^{\circ} \mathrm{C}$ for $8 \mathrm{~h}$ in a Thioflavin T assay. After $2 \mathrm{~h}$ incubation, $\mathrm{A} \beta$ aggregation (black squares) entered a phase of rapid kinetic growth representing fibrillization. As expected, fluorescence measurements from PBS alone (white squares) remained unchanged. Values shown are means of duplicate measurements $(n=2)$. B) A $\beta_{42}$ multimeric species $(2 \mu \mathrm{g})$ generated by a $2 \mathrm{~h}$ aggregation protocol were separated on a $4-12 \%$ Tris-Bis $\mathrm{NuPAGE}^{\circledR}$ gel and visualized using a monoclonal anti-A $\beta$ antibody (6E10). A strong band of oligomers ranging from $45-220 \mathrm{kDa}$ is visible (lane 2), in comparison to only monomers, dimers and trimers in the control, non-aggregated $\mathrm{A} \beta_{42}$ (lane 1).

with previously published studies $[49,54]$. Since we were specifically interested in inducing damage to phospholipid membranes by non-fibrillar $\mathrm{A} \beta$ structures, only aggregates with low ThT fluorescence were selected for further study.

\section{$A \beta_{42}$ oligomers evoke dose-dependent permeabilization of DOPE:DOPS:DOPC liposomes}

A permeabilization assay was conducted, comparing the perforation ability of $\mathrm{A} \beta_{42}$ aggregates formed after 1,2 , or $3 \mathrm{~h}$ incubation at $37^{\circ} \mathrm{C}$. The strongest permeabilization effect was observed with the 2 -h and 3-h aggregates (31.2\% and 30\%, respectively; Fig. 2), whilst $A \beta_{42}$ peptides incubated for only $1 \mathrm{~h}$ had a significantly weaker effect $(23.9 \% ; p=0.027)$. Therefore, on the basis of a combination of low ThT fluorescence and robust membrane perforation, we opted for the $2 \mathrm{~h}$ aggregation to standardize our $A \beta$ oligomerization protocol. Moreover, $A \beta_{42}$ multimers resulting from a $2 \mathrm{~h}$ aggregation were separated and visualized by immunoblotting (Fig. 1B). This confirmed formation of oligomers ranging in size from $45-220 \mathrm{kDa}$, i.e., in the high-molecular-weight (HMW) range. These oligomers were capable of inducing immediate

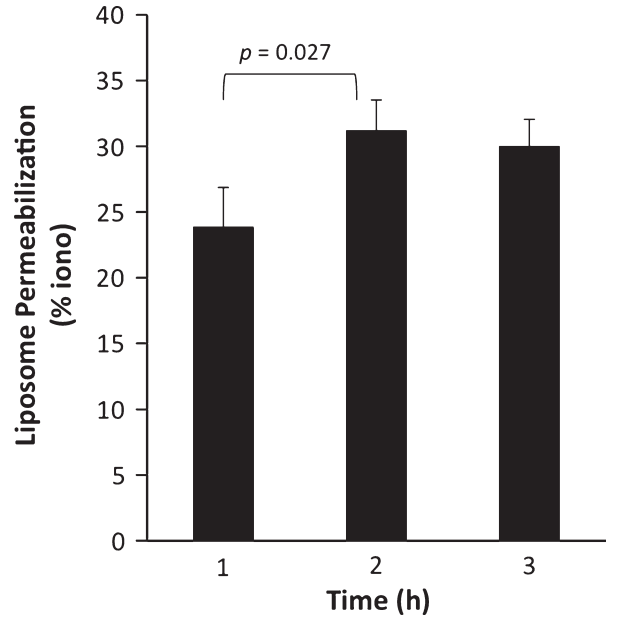

Fig. 2. Lipid vesicle permeabilization by $A \beta_{42}$ oligomers. $2.5 \mu \mathrm{M}$ $\mathrm{A} \beta$ (aggregated for 1,2 , or $3 \mathrm{~h}$ ) was added to $25 \mu \mathrm{M}$ OG-filled liposomes. Values are given as a percentage of ionomycin-induced liposome permeabilization (theoretical max., 100\%) and represent means $\pm \operatorname{SEM}(n=3)$.

permeabilization of SUVs at $0.25-5 \mu \mathrm{M}$ (in moles of monomeric peptide), in most cases reaching a maximal effect within 15 min (Fig. 3). Permeabilization by the $A \beta$ oligomers was calculated as percentage of the ionomycin effect (a calcium ionophore): $15.7 \% \pm 1.3$ $(0.25 \mu \mathrm{M}), \quad 24.7 \% \pm 7.5 \quad(0.5 \mu \mathrm{M}), \quad 25.8 \% \pm 5.6$ 


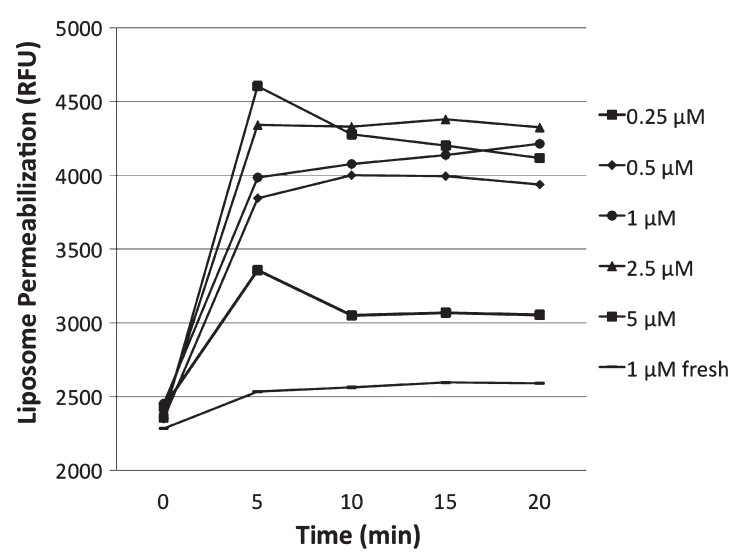

Fig. 3. Kinetics of lipid vesicle permeabilization by $A \beta_{42}$ oligomers. $0.25-5 \mu \mathrm{M}$ of $\mathrm{A} \beta$ oligomers (in terms of moles of monomeric protein) were added to OG-filled vesicles, as described in "Materials and Methods". A dose-dependent effect upon the kinetics of liposome permeabilization is shown. Conversely, $1 \mu \mathrm{M}$ fresh (nonaggregated) $A \beta_{42}$ left the lipid vesicles intact. Values shown in graph were obtained from one experiment, out of at least three independent measurements yielding quantitatively identical results.

$(1.0 \mu \mathrm{M}), 25.2 \% \pm 5.0(2.5 \mu \mathrm{M})$, and $30.6 \% \pm 3.5$ $(5 \mu \mathrm{M})$. Importantly, lipid vesicles remained intact following exposure to $1 \mu \mathrm{M}$ fresh (non-aggregated) $\mathrm{A} \beta_{42}$ (Fig. 3). These results suggest that $0.5-1 \mu \mathrm{M}$ aggregated $A \beta_{42}$ was sufficient to cause defects in the lipid bilayer that result in increased membrane permeability. However, a $1 \mu \mathrm{M}$ concentration was more robust than $0.5 \mu \mathrm{M}$ in giving a minimum permeabilization of more than $20 \%(0.5 \mu \mathrm{M}: 24.7 \% \pm 7.5$; $1.0 \mu \mathrm{M}: 25.8 \% \pm 5.6)$. Therefore, $1 \mu \mathrm{M} \mathrm{A} \beta_{42}$ was typically chosen for subsequent experiments.

Finally, we wanted to characterize better the mode of membrane destabilization by $A \beta$, for instance, whether by channel, pore formation or total disruption of the vesicle membrane. Thus, a size-dependent fluorescence leakage assay was performed by preparing liposomes containing FITC-dextrans of two different molecular sizes $(40 \mathrm{kDa}$ or $70 \mathrm{kDa})$ and exposing them to $1 \mu \mathrm{M} \mathrm{A} \beta_{42}$ oligomers. The leakage of the differentially-sized markers occurred as follows: $46.9 \% \pm 2.6(1 \mathrm{kDa}), 38.3 \% \pm 2.6(40 \mathrm{kDa})$, and $39.3 \% \pm 2.9(70 \mathrm{kDa})$. Although there was a minor decrease in leakage of the larger-sized dextrans, this difference was not statistically significant $(p=0.07)$.

\section{Inhibitory effects of natural polyphenols and BTE on lipid vesicle permeabilization by $A \beta_{42}$ oligomers}

Having established a reproducible protocol for lipid vesicle permeabilization by $A \beta_{42}$ oligomers, we pro- ceeded to test the inhibitory effects of 15 plant polyphenols and BTE. The compounds were allowed to interact with pre-aggregated $A \beta_{42}$ before adding liposomes; this approach allowed the compounds to antagonize vesicle disruption by destabilizing the toxic $\mathrm{A} \beta$ species and/or by interfering with the binding of $\mathrm{A} \beta$ oligomers to the lipid vesicle membranes. The results are summarized in Fig. 4A. Overall, addition of plant polyphenols and BTE led to a decrease in the vesicle permeabilization induced by $A \beta_{42}$ aggregates alone, ranging from $90 \%$ permeabilization (weak inhibitory effect) to $4 \%$ permeabilization (very strong inhibitory effect). Compounds were hence classified as follows:

- Group I - very strong inhibitors ( $<10 \%$ permeabilization) BTE (4\%).

- Group II - strong-to-moderate inhibitors (10-49\% permeabilization) Baic (22\%), Api (27\%), NDGA (29\%), Purp (35\%) and Scut (45\%).

- Group III - moderate-to-weak inhibitors (50-79\% permeabilization) Rosm (58\%), EGCG (67\%) and Quer (73\%).

- Group IV - weak inhibitors (80-95\% permeabilization) Myr (80\%), Cat (80\%), Gen (80\%), Mor $(81 \%)$, Fis $(82 \%)$, Gink $(84 \%)$ and Resv $(90 \%)$

A select group of three compounds from Groups I and II (BTE, NDGA and Purp) were subsequently tested for concentration-dependency in the range $10-100 \mu \mathrm{M}$ (or $1-15 \mu \mathrm{g} / \mathrm{ml}$ in the case of BTE), using the liposome permeabilization assay. NDGA remained moderately effective even at $20 \mu \mathrm{M}(60 \%)$, whilst BTE was still a potent inhibitor at $5 \mu \mathrm{g} / \mathrm{ml}(<10 \%$; Fig. 4B).

Synergistic inhibition by pairwise combinations of polyphenols

It was hypothesized that combinations of smallmolecule compounds could manifest a stronger, synergistic, inhibitory effect than either compound alone. Thus, pairwise associations of Api, NDGA, and Purp were investigated for their inhibition of $\mathrm{A} \beta$-induced lipid vesicle membrane destabilization (Fig. 5). A synergistic effect was observed only with the Purp-Api combination: $10 \mu \mathrm{M}$ Purp alone (94\%), $10 \mu \mathrm{M}$ Api alone (80\%), $10 \mu \mathrm{M}$ Purp-Api (48\%). The other combinations showed at most additive, but not synergistic, effects (data not shown). 

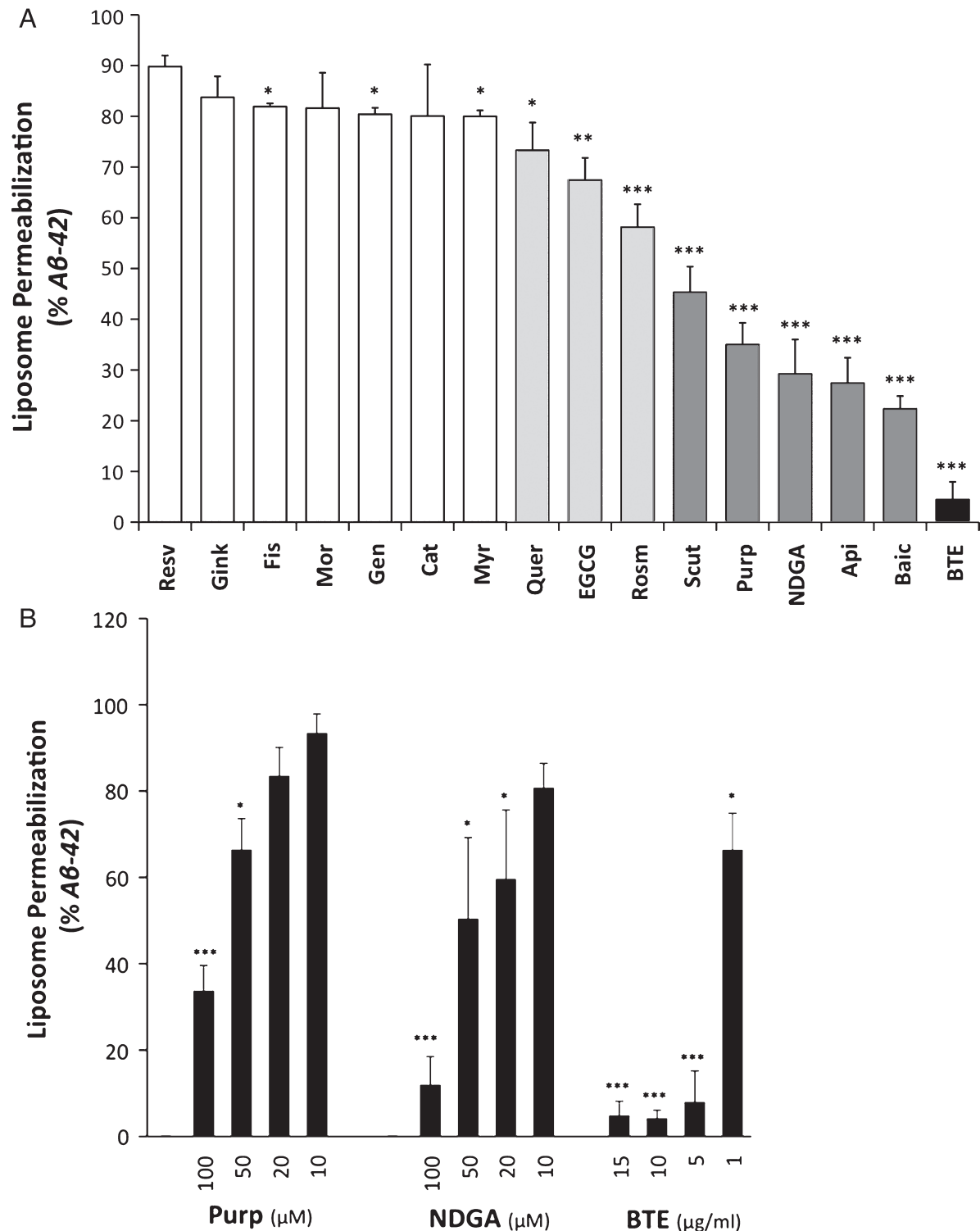

Fig. 4. Effects of polyphenols and black tea extract on lipid vesicle permeabilization by A $\beta_{42}$ oligomers. A) Polyphenols (50 $\left.\mu \mathrm{M}\right)$ and BTE $(15 \mu \mathrm{g} / \mathrm{ml})$ were incubated for 10 min with $1 \mu \mathrm{M}$ pre-aggregated $\mathrm{A} \beta_{42}$, after which $25 \mu \mathrm{M}$ liposomes were added to monitor permeabilization. Based on their inhibitory effects, the compounds were classified into 4 groups: very strong (black column), strong-to-moderate (dark gray columns), moderate-to-weak (light gray columns), and weak (white columns). B) Concentration-dependent inhibition of liposome permeabilization by purpurogallin trimetyl ether (Purp), NDGA and black tea extract (BTE). Liposome permeabilization in presence of compounds is given as a percentage of the effect of $\mathrm{A} \beta$ alone $\left(\% \mathrm{~A} \beta_{42}, \mathrm{y}\right.$-axis). Values represent means $\pm \mathrm{SEM}(n \geq 3) ; * p<0.05, * * p<0.01, * * * p<0.005$ versus $A \beta_{42}$.

\section{Inhibition of $A \beta_{42}$-induced lipid vesicle permeabilization by synthetic $N^{\prime}$-Benzylidene- Benzohydrazide (NBB) compounds}

Next, eight synthetic NBB compounds (NBB \#1-8) were also tested by the liposome permeabilization inhibition assay (at $10 \mu \mathrm{M}$ ). The NBB compounds were compared directly to the top natural polyphenols identified by the previous screening (also at $10 \mu \mathrm{M}$ ). This allowed identification of three NBB compounds that were as potent as Baic, Api, and NDGA in protecting lipid vesicle membranes from $A \beta$ permeabilization (Fig. 6): NBB \#6 (80\%), NBB \#7 (80\%) and NBB \#8 (67\%). 




Fig. 5. Effect of compound combination on $A \beta$-induced liposome permeabilization. Paired combination of $10 \mu \mathrm{M}$ Purp and $10 \mu \mathrm{M}$ Api reveals a synergistic potentiation of their inhibitory effect against liposome permeabilization by $A \beta_{42}$. Values shown here are mean of triplicate readings $\pm \operatorname{SEM}(n=2) ; * * p<0.01, * * * p<0.005$.

\section{DISCUSSION}

Maintenance of plasma membrane integrity is crucial for neuronal function. In this regards, there is accumulating evidence that prefibrillar A $\beta$ oligomers are the primary neurotoxic species in $\mathrm{AD}$ [55] and that disturbance of neuronal membranes is a likely first step in the pathophysiological cascade initiated by these oligomers [56]. Therefore, we first sought to generate soluble high-molecular-weight $A \beta_{42}$ oligomers and confirmed that they robustly compromised membranes of model unilamellar liposomes at near-physiological concentrations. Of note, 'fresh' $A \beta_{42}$ peptides (consisting of monomers and very small oligomeric species) were unable to induce vesicle permeabilization. This is in agreement with several reports of increased membrane conductance and permeability by prefibrillar $A \beta$ oligomers, but not by near-monomeric species [17, 57-59]. Large assemblies of $A \beta$ molecules have in fact been detected attached to live cell membranes [60]. As a point of clarification, it cannot be excluded that further conformational conversion takes place upon interaction of the oligomers with lipid membranes. For example, phosphatidylcholine



Fig. 6. Effect of $10 \mu \mathrm{M}$ NBB derivates on $\mathrm{A} \beta$-induced liposome permeabilization. Lipid vesicle permeabilization was assessed by adding $25 \mu \mathrm{M}$ liposomes following incubation of $10 \mu \mathrm{M}$ NBB derivatives (1-8; gray columns) and solvent control (CTR; white column) with $1 \mu \mathrm{M}$ pre-aggregated $\mathrm{A} \beta_{42}$ for $10 \mathrm{~min}$. For direct comparison, $10 \mu \mathrm{M}$ Api and $10 \mu \mathrm{M}$ Baic were included in the screen (black columns). Values shown are percentage of $\mathrm{A} \beta_{42}$ effect $\left(\% \mathrm{~A} \beta_{42} ; \mathrm{y}\right.$-axis). Values represent means $\pm \operatorname{SEM}(n=3) ; * p<0.05, * * p<0.01, * * * p<0.005$ versus $A \beta_{42}$. 
vesicles catalyzed the conversion of attached prefibrillar oligomers into pore-like annular protofibrils [61].

Most of the fluorescent dye leakage occurred rapidly during the first $5 \mathrm{~min}$, similar to what has been described previously [62]. In order to explore the possibility that the $A \beta$ aggregates might be forming pores within liposome membranes, the differences in leakage between 1-kDa, 40-kDa and 70-kDa fluorophores was determined and found not to be statistically significant, implying either complete disruption of the membrane or a large-pore forming mechanism. Interestingly, it has been reported that pores formed by A $\beta$ in situ, in the neuronal cell membrane in $\mathrm{AD}$ brain, had a lumen of $\sim 10 \mathrm{~nm}$ [63]. Such large $A \beta$ pores would be expected to allow molecules, certainly up to the size of $100 \mathrm{kDa}$, to leak out freely. Therefore, a permeabilization mechanism involving pore formation by the HMW $A \beta_{42}$ aggregates cannot be excluded a priori. It is relevant to point out here that poreforming proteins, like the bacterial toxin $\alpha$-hemolysin and human perforin, share structural homology with amyloid oligomers suggesting a common mechanism of membrane permeabilization [64].

The ability of small molecule compounds and black tea extract to protect phospholipid membranes from disruption by $A \beta$ aggregates was tested using our permeabilization assay. Out of 15 natural polyphenols, 8 $\mathrm{N}^{\prime}$-benzylidene-benzohydrazide derivatives and BTE, the most active was in fact the tea extract. At $5 \mu \mathrm{g} / \mathrm{ml}$, BTE still prevented the membrane-disordering effect of $A \beta_{42}$ oligomers to less than $10 \%$ of control $A \beta$ alone. Our assay result is supported by recent human epidemiological and animal data suggesting that tea drinking may help protect the aging brain and reduce the incidence of dementia or AD [65]. Thus, interfering with oligomer-induced lipid membrane damage may represent a key modality in the treatment of $\mathrm{AD}$ neurodegeneration.

The basic flavonoid structure is the flavan core, which consists of a 15 carbon skeleton (C6-C3-C6), arranged in three rings labeled as A, B, and C (Fig. 7). The various classes of flavonoids differ in the level of oxidation and pattern of substitution of the $\mathrm{C}$ ring. These include the flavonols (e.g., Fis, Mor, Myr, Quer), the flavanols (e.g., EGCG, Cat), the flavones (e.g., Api, Baic, Scut), and the isoflavones (e.g., Gen). Individual compounds within a class differ in the pattern of substitution of the A and B rings. Apart from the very strong activity of BTE, five small-molecule polyphenols were classified as "strong-to-moderate" inhibitors since they decreased liposome permeabi- lization to $10-49 \%$. Notably, of these five compounds, three are flavones: 5,6,7-trihydroxyflavone (Baic), 4',5,7-trihydroxyflavone (Api), and 4',5,6,7tetrahydroxyflavone (Scut). Examining these three structures, a common 5,7-dihydroxyflavone scaffold appears to be a prominent feature (Fig. 7). In contrast, the weaker flavonols Fis, Mor, Myr, and Quer possess a hydroxyl group attached to C3. Moreover, Cat and EGCG, as well as the isoflavone Gen, have the $\mathrm{B}$ ring of the flavonoid molecule attached to C3. Evidently, substitutions at the $\mathrm{C} 3$ position have profound negative effects on the ability of the polyphenol molecule to attenuate membrane permeabilization.

Another strong inhibitor of lipid membrane damage by the $A \beta_{42}$ oligomers is NDGA, which shares a 6,7dihydroxyphenyl ring structure with the A ring of Baic and Api (Fig. 7). Interestingly, dihydroxyphenyl rings are a recurring feature of the three synthetic NBB compounds (NBB \#6-8; 307F06, 301C09, and 293G02, respectively) with inhibitory activities similar to Api, Baic, and NDGA. To conclude, intuitive recognition of the structural relationships associated with highest inhibitory activity allows derivation of the 'scaffold tree' shown in Fig. 7: essentially, a dihydroxyphenyl ring alone, or as part of a flavone module with a preferred maximum of 3 hydroxyl groups, is particularly adapted for protection against membrane damage by $\mathrm{A} \beta$ oligomers. These structure-activity relationships may also be of importance when considering treatment with combinations of small-molecule compounds. For instance, we noted a synergistic effect between Api and Purp: the paired compounds at $10 \mu \mathrm{M}$ were almost as strong as either compound alone at five times that concentration. The synergism implies a different mode of action of these two molecules, which represent in fact a combination of an apolar (Purp) and polar (Api) chemical structures.

The molecular mechanisms underlying preservation of membrane integrity by BTE and phenolic compounds is currently under investigation. First of all, rescue may depend upon interaction of compounds with the oligomers themselves. This would lead to dissociation and/or remodeling of the oligomers into harmless $A \beta$ species. Substantial data has been published on the ability of the studied inhibitors to inhibit $A \beta$ aggregation and/or destabilize formed assemblies in vitro [66-69]. Importantly, however, in all of these assays $A \beta$ aggregation was tested in the absence of lipids. Indeed, when comparing these reported anti-amyloidogenic properties of polyphenols, on one hand, with our results from the liposome 
<smiles>O=c1cc(-c2ccc(O)cc2)oc2cc(O)cc(O)c12</smiles><smiles>O=C(O[Na])Oc1ccc(C(=O)N/N=C/c2ccc3ccccc3c2)cc1C(=O)NN=Cc1ccc2ccccc2c1</smiles><smiles>CC(C)(C)Oc1cc2oc(-c3ccccc3)cc(=O)c2c(O)c1O</smiles><smiles>Cc1cccc(C=NNC(=O)c2ccc(O)c(O)c2)c1</smiles>

\section{NDGA}

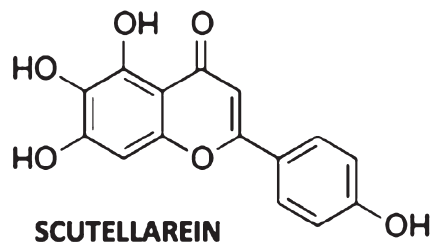<smiles>CC(Cc1ccc(O)c(O)c1)C(C)Cc1ccc(O)c(O)c1</smiles><smiles>O=c1cc(-c2ccccc2)oc2cc(O)cc(O)c12</smiles>

Fig. 7. Chemical structures of the top small-molecule compounds inhibiting $A \beta$-induced liposome permeabilization. The flavone polyphenols: apigenin (4',5,7-trihydroxyflavone), baicalein (5,6,7-trihydroxyflavone) and scutellarein (4',5,6,7-tetrahydroxyflavone). A shared criterion is thus the 5,7-dihydroxyflavone structure; note the15 carbon skeleton (C6-C3-C6) of a flavan core, arranged in three rings labeled as A, B, and C. Another strong inhibitor was found to be the polyphenol NDGA, which shares a 6,7-dihydroxyphenyl ring structure with the A ring of baicalein and apigenin. Dihydroxyphenyl rings are common to the three top-scoring $\mathrm{N}^{\prime}$-benzylidene-benzohydrazide compounds (307F06, 301C09 and 293G02).

permeabilization assay, on the other, we find no significant correlation between the two. For example, Api was found to be a very weak inhibitor of $A \beta_{42}$ aggregation $\left(\mathrm{IC}_{50}>40 \mu \mathrm{M}\right)$, and Baic $\left(\mathrm{IC}_{50}=5.3 \mu \mathrm{M}\right)$ was at least an order of magnitude less potent than other flavonoids such as $\mathrm{Myr}\left(\mathrm{IC}_{50}=0.67 \mu \mathrm{M}\right)$, Mor $\left(\mathrm{IC}_{50}=0.4 \mu \mathrm{M}\right)$, Quer $\left(\mathrm{IC}_{50}=0.72 \mu \mathrm{M}\right)$, or EGCG $\left(\mathrm{IC}_{50}=0.18 \mu \mathrm{M}\right)$. These observations seem to suggest, therefore, that mechanisms involving direct binding of the compounds to $A \beta$ multimeric structures leading to their complete disassembly [31] are not likely to be primarily involved. The possibility still remains, notwithstanding, that compounds like Api and Baic remodel the soluble oligomers into larger aggregates that are non-toxic to membranes [70]. The exception appears to be NDGA, which has a known potent anti-amyloidogenic and fibril destabilizing activity $\left(\mathrm{IC}_{50}=0.74-1.1 \mu \mathrm{M} 0\right.$ [69]. NDGA is composed differently from the flavones, and has two relatively polar aromatic groups (the dihydroxyphenyl rings discussed 
above) connected by a rigid linker. Interestingly, effective molecules from the NBB derivates (NBB \#6-8) have an analogous structure to NDGA, with a dihydroxyphenyl ring at one end of the molecule, a phenyl ring at the other and a central linker. It is also striking that the top NBB compound in our liposome permeabilization assay, NBB \#8 (293G02), correlates nicely with previously published findings: $293 \mathrm{G} 02$ was also the best NBB compound to demonstrate anti-prion activity in a high-throughout screening assay [71], to potently inhibit polyQ aggregation [72] and to interfere with alpha-synuclein oligomer formation in living cells [73].

Another possible mechanism would involve modulation of the oligomer-membrane interaction by the compounds, particularly the polyphenols. A flavonoiddependent effect on the lipid bilayer may explain, in part, the preservation of membrane integrity by the compounds. It has been shown recently that flavonoids partially penetrate bilayer membranes, resulting in a strong rigidifying effect on the bilayer structure. Consequently, membranes exposed to flavonoids loose the ability to interact with $A \beta$ peptide [40].

\section{CONCLUSION}

We report here a novel study on the effects of small-molecule natural and synthetic compounds, and black tea extract, on the permeabilization of lipid vesicles by $A \beta_{42}$ oligomers. Based upon our data, we encourage more in-depth studies on the potential disease-modifying effects of black tea in AD. Apart from tea extract, the common structural criterion shared by the potent inhibitors (Api, Baic, Scut, NDGA, 307F06, 301C09, and 293G02) is the presence of a dihydroxyphenyl ring structure, alone or as part of a flavone scaffold. Having identified this active skeleton, combinatorial chemistry can be used as a means for further structural compound optimization [74]. Given that neuronal phospholipid membranes are considered a primary target of $A \beta$ oligomers, it follows that development of such compounds would help meet the momentous therapeutic challenge represented by AD.

\section{ACKNOWLEDGMENTS}

This work was mainly supported by the Malta Council for Science and Technology (R\&I-2008-068, 'Neuroamyloid'). Other financial contributors include the University of Malta (R09-31-309) and the Deutsche Forschungsgemeinschaft. We would also like to thank Mr. Charles Saliba and Ms. Rachel Cremona of the Institute of Cellular Pharmacology Ltd. (Mosta Technopark, Malta) for their collaboration.

Authors' disclosures available online (http://www.jalz.com/disclosures/view.php?id=955).

\section{REFERENCES}

[1] Ballard C, Gauthier S, Corbett A, Brayne C, Aarsland D, Jones E (2011) Alzheimer's disease. Lancet 377, 1019-1031.

[2] Ritchie K, Lovestone S (2002) The dementias. Lancet 360, 1759-1766.

[3] Crews L, Masliah E (2010) Molecular mechanisms of neurodegeneration in Alzheimer's disease. Hum Mol Genet 19, R12-R20.

[4] Hardy J (2009) The amyloid hypothesis for Alzheimer's disease: A critical reappraisal. J Neurochem 110, 1129-1134.

[5] Ahmed M, Davis J, Aucoin D, Sato T, Ahuja S, Aimoto S, Elliott JI, Van Nostrand WE, Smith SO (2010) Structural conversion of neurotoxic amyloid-beta(1-42) oligomers to fibrils. Nat Struct Mol Biol 17, 561-567.

[6] Perl DP (2000) Neuropathology of Alzheimer's disease and related disorders. Neurol Clin 18, 847-864.

[7] Luheshi LM, Tartaglia GG, Brorsson AC, Pawar AP, Watson IE, Chiti F, Vendruscolo M, Lomas DA, Dobson CM, Crowther DC (2007) Systematic in vivo analysis of the intrinsic determinants of amyloid Beta pathogenicity. PLoS Biol 5 , e290.

[8] Walsh DM, Klyubin I, Fadeeva JV, Cullen WK, Anwyl R, Wolfe MS, Rowan MJ, Selkoe DJ (2002) Naturally secreted oligomers of amyloid beta protein potently inhibit hippocampal long-term potentiation in vivo. Nature 416, 535-539.

[9] Walsh DM, Selkoe DJ (2004) Oligomers on the brain: The emerging role of soluble protein aggregates in neurodegeneration. Protein Pept Lett 11, 213-228.

[10] Selkoe DJ (2008) Soluble oligomers of the amyloid betaprotein impair synaptic plasticity and behavior. Behav Brain Res 192, 106-113.

[11] Takamura A, Okamoto Y, Kawarabayashi T, Yokoseki T, Shibata M, Mouri A, Nabeshima T, Sun H, Abe K, Urisu T, Yamamoto N, Shoji M, Yanagisawa K, Michikawa M, Matsubara E (2011) Extracellular and intraneuronal HMWAbetaOs represent a molecular basis of memory loss in Alzheimer's disease model mouse. Mol Neurodegene 6, 20.

[12] Cleary JP, Walsh DM, Hofmeister JJ, Shankar GM, Kuskowski MA, Selkoe DJ, Ashe KH (2005) Natural oligomers of the amyloid-beta protein specifically disrupt cognitive function. Nat Neurosci 8, 79-84.

[13] Reed MN, Hofmeister JJ, Jungbauer L, Welzel AT, Yu C, Sherman MA, Lesne S, Ladu MJ, Walsh DM, Ashe KH, Cleary JP (2011) Cognitive effects of cell-derived and synthetically derived Abeta oligomers. Neurobiol Aging 32, 1784-1794.

[14] Kokubo H, Kayed R, Glabe CG, Staufenbiel M, Saido TC, Iwata N, Yamaguchi H (2009) Amyloid beta annular protofibrils in cell processes and synapses accumulate with aging and Alzheimer-associated genetic modification. Int J Alzheimers Dis pii: $689285,1-7$

[15] Eckert GP, Wood WG, Muller WE (2010) Lipid membranes and beta-amyloid: A harmful connection. Curr Protein Pept Sci 11, 319-325.

[16] Kremer JJ, Sklansky DJ, Murphy RM (2001) Profile of changes in lipid bilayer structure caused by beta-amyloid peptide. Biochemistry 40, 8563-8571. 
[17] Kayed R, Sokolov Y, Edmonds B, McIntire TM, Milton SC, Hall JE, Glabe CG (2004) Permeabilization of lipid bilayers is a common conformation-dependent activity of soluble amyloid oligomers in protein misfolding diseases. $J$ Biol Chem 279, 46363-46366

[18] de Planque MR, Raussens V, Contera SA, Rijkers DT, Liskamp RM, Ruysschaert JM, Ryan JF, Separovic F, Watts A (2007) Beta-Sheet structured beta-amyloid(1-40) perturbs phosphatidylcholine model membranes. J Mol Biol 368, 982997.

[19] Davis CH, Berkowitz ML (2009) Interaction between amyloid-beta (1-42) peptide and phospholipid bilayers: A molecular dynamics study. Biophys J 96, 785-797.

[20] Arispe N, Pollard HB, Rojas E (1994) The ability of amyloid beta-protein [A beta $\mathrm{P}(1-40)$ ] to form $\mathrm{Ca} 2+$ channels provides a mechanism for neuronal death in Alzheimer's disease. Ann N Y Acad Sci 747, 256-266.

[21] Lin H, Bhatia R, Lal R (2001) Amyloid beta protein forms ion channels: Implications for Alzheimer's disease pathophysiology. FASEB J 15, 2433-2444.

[22] Arispe N, Diaz JC, Simakova O (2007) Abeta ion channels. Prospects for treating Alzheimer's disease with Abeta channel blockers. Biochim Biophys Acta 1768, 1952-1965.

[23] Kawahara M (2010) Neurotoxicity of beta-amyloid protein: Oligomerization, channel formation, and calcium dyshomeostasis. Curr Pharm Des 16, 2779-2789.

[24] Kawahara M, Ohtsuka I, Yokoyama S, Kato-Negishi M, Sadakane Y (2011) Membrane incorporation, channel formation, and disruption of calcium homeostasis by Alzheimer's beta-amyloid protein. Int J Alzheimers Dis 2011, 304583.

[25] Simakova O, Arispe NJ (2007) The cell-selective neurotoxicity of the Alzheimer's Abeta peptide is determined by surface phosphatidylserine and cytosolic ATP levels. Membrane binding is required for Abeta toxicity. J Neurosci 27, 1371913729.

[26] Hung LW, Ciccotosto GD, Giannakis E, Tew DJ, Perez K, Masters CL, Cappai R, Wade JD, Barnham KJ (2008) Amyloid-beta peptide (Abeta) neurotoxicity is modulated by the rate of peptide aggregation: Abeta dimers and trimers correlate with neurotoxicity. J Neurosci 28, 1195011958.

[27] Diaz JC, Simakova O, Jacobson KA, Arispe N, Pollard HB (2009) Small molecule blockers of the Alzheimer Abeta calcium channel potently protect neurons from Abeta cytotoxicity. Proc Natl Acad Sci U S A 106, 3348-3353.

[28] Sepulveda FJ, Parodi J, Peoples RW, Opazo C, Aguayo LG (2010) Synaptotoxicity of Alzheimer beta amyloid can be explained by its membrane perforating property. PLoS One 5, e11820.

[29] Kostka M, Hogen T, Danzer KM, Levin J, Habeck M, Wirth A, Wagner R, Glabe CG, Finger S, Heinzelmann U, Garidel P, Duan W, Ross CA, Kretzschmar H, Giese A (2008) Single particle characterization of iron-induced poreforming alpha-synuclein oligomers. J Biol Chem 283, 1099211003.

[30] Bastianetto S, Krantic S, Quirion R (2008) Polyphenols as potential inhibitors of amyloid aggregation and toxicity: Possible significance to Alzheimer's disease. Mini Rev Med Chem 8, 429-435.

[31] Lemkul JA, Bevan DR (2010) Destabilizing Alzheimer's Abeta(42) protofibrils with morin: Mechanistic insights from molecular dynamics simulations. Biochemistry 49, 39353946.

[32] Thapa A, Woo ER, Chi EY, Sharoar MG, Jin HG, Shin SY, Park IS (2011) Biflavonoids are superior to monoflavonoids in inhibiting amyloid-beta toxicity and fibrillogenesis via accumulation of nontoxic oligomer-like structures. Biochemistry 50, 2445-2455.

[33] Caruana M, Hogen T, Levin J, Hillmer A, Giese A, Vassallo $\mathrm{N}$ (2011) Inhibition and disaggregation of alpha-synuclein oligomers by natural polyphenolic compounds. FEBS Lett 585, 1113-1120.

[34] Manach C, Scalbert A, Morand C, Remesy C, Jimenez L (2004) Polyphenols: Food sources and bioavailability. Am J Clin Nutr 79, 727-747.

[35] Scalbert A, Williamson G (2000) Dietary intake and bioavailability of polyphenols. J Nutr 130, 2073S-2085S.

[36] Quideau S, Deffieux D, Douat-Casassus C, Pouysegu L (2011) Plant polyphenols: Chemical properties, biological activities, and synthesis. Angew Chem Int Ed Engl 50, 586-621.

[37] Oteiza PI, Erlejman AG, Verstraeten SV, Keen CL, Fraga CG (2005) Flavonoid-membrane interactions: A protective role of flavonoids at the membrane surface? Clin Dev Immunol 12, 19-25.

[38] Ollila F, Halling K, Vuorela P, Vuorela H, Slotte JP (2002) Characterization of flavonoid-biomembrane interactions. Arch Biochem Biophys 399, 103-108.

[39] Arora A, Byrem TM, Nair MG, Strasburg GM (2000) Modulation of liposomal membrane fluidity by flavonoids and isoflavonoids. Arch Biochem Biophys 373, 102-109.

[40] Tedeschi A, D’Errico G, Lauro MR, Sansone F, Di Marino S, D'Ursi AM, Aquino RP (2010) Effect of flavonoids on the Abeta(25-35)-phospholipid bilayers interaction. Eur J Med Chem 45, 3998-4003.

[41] Rezai-Zadeh K, Arendash GW, Hou H, Fernandez F, Jensen M, Runfeldt M, Shytle RD, Tan J (2008) Green tea epigallocatechin-3-gallate (EGCG) reduces beta-amyloid mediated cognitive impairment and modulates tau pathology in Alzheimer transgenic mice. Brain Res 1214, 177-187.

[42] Wang J, Ho L, Zhao W, Ono K, Rosensweig C, Chen L, Humala N, Teplow DB, Pasinetti GM (2008) Grape-derived polyphenolics prevent Abeta oligomerization and attenuate cognitive deterioration in a mouse model of Alzheimer's disease. J Neurosci 28, 6388-6392.

[43] Ho L, Chen LH, Wang J, Zhao W, Talcott ST, Ono K, Teplow D, Humala N, Cheng A, Percival SS, Ferruzzi M, Janle E, Dickstein DL, Pasinetti GM (2009) Heterogeneity in red wine polyphenolic contents differentially influences Alzheimer's disease-type neuropathology and cognitive deterioration. $J$ Alzheimers Dis 16, 59-72.

[44] Hamaguchi T, Ono K, Murase A, Yamada M (2009) Phenolic compounds prevent Alzheimer's pathology through different effects on the amyloid-beta aggregation pathway. Am J Pathol 175, 2557-2565.

[45] Parachikova A, Green KN, Hendrix C, LaFerla FM (2010) Formulation of a medical food cocktail for Alzheimer's disease: Beneficial effects on cognition and neuropathology in a mouse model of the disease. PLoS One 5, e14015.

[46] Meydani M (2001) Nutrition interventions in aging and ageassociated disease. Ann N Y Acad Sci 928, 226-235.

[47] Bastianetto S, Quirion R (2002) Natural extracts as possible protective agents of brain aging. Neurobiol Aging 23, 891897.

[48] Kim J, Lee HJ, Lee KW (2010) Naturally occurring phytochemicals for the prevention of Alzheimer's disease. $J$ Neurochem 112, 1415-1430.

[49] Necula M, Kayed R, Milton S, Glabe CG (2007) Small molecule inhibitors of aggregation indicate that amyloid beta oligomerization and fibrillization pathways are independent and distinct. J Biol Chem 282, 10311-10324. 
[50] El-Agnaf OM, Paleologou KE, Greer B, Abogrein AM, King JE, Salem SA, Fullwood NJ, Benson FE, Hewitt R, Ford KJ, Martin FL, Harriott P, Cookson MR, Allsop D (2004) A strategy for designing inhibitors of alpha-synuclein aggregation and toxicity as a novel treatment for Parkinson's disease and related disorders. FASEB J 18, 1315-1317.

[51] Takamori S, Holt M, Stenius K, Lemke EA, Gronborg M, Riedel D, Urlaub H, Schenck S, Brugger B, Ringler P, Muller SA, Rammner B, Grater F, Hub JS, De Groot BL, Mieskes G, Moriyama Y, Klingauf J, Grubmuller H, Heuser J, Wieland F, Jahn R (2006) Molecular anatomy of a trafficking organelle. Cell 127, 831-846.

[52] Blau L, Weissmann G (1988) Transmembrane calcium movements mediated by ionomycin and phosphatidate in liposomes with Fura 2 entrapped. Biochemistry 27, 5661-5666.

[53] Naiki H, Gejyo F (1999) Kinetic analysis of amyloid fibril formation. Methods Enzymol 309, 305-318.

[54] Hortschansky P, Schroeckh V, Christopeit T, Zandomeneghi G, Fandrich M (2005) The aggregation kinetics of Alzheimer's beta-amyloid peptide is controlled by stochastic nucleation. Protein Sci 14, 1753-1759.

[55] Cizas P, Budvytyte R, Morkuniene R, Moldovan R, Broccio M, Losche M, Niaura G, Valincius G, Borutaite V (2010) Sizedependent neurotoxicity of beta-amyloid oligomers. Arch Biochem Biophys 496, 84-92.

[56] Demuro A, Mina E, Kayed R, Milton SC, Parker I, Glabe CG (2005) Calcium dysregulation and membrane disruption as a ubiquitous neurotoxic mechanism of soluble amyloid oligomers. J Biol Chem 280, 17294-17300.

[57] Sokolov Y, Kozak JA, Kayed R, Chanturiya A, Glabe C, Hall JE (2006) Soluble amyloid oligomers increase bilayer conductance by altering dielectric structure. J Gen Physiol 128, 637-647.

[58] Valincius G, Heinrich F, Budvytyte R, Vanderah DJ, McGillivray DJ, Sokolov Y, Hall JE, Losche M (2008) Soluble amyloid beta-oligomers affect dielectric membrane properties by bilayer insertion and domain formation: Implications for cell toxicity. Biophys J 95, 4845-4861.

[59] Schauerte JA, Wong PT, Wisser KC, Ding H, Steel DG, Gafni A (2010) Simultaneous single-molecule fluorescence and conductivity studies reveal distinct classes of Abeta species on lipid bilayers. Biochemistry 49, 3031-3039.

[60] Nag S, Chen J, Irudayaraj J, Maiti S (2010) Measurement of the attachment and assembly of small amyloid-beta oligomers on live cell membranes at physiological concentrations using single-molecule tools. Biophys J 99, 1969-1975.

[61] Kayed R, Pensalfini A, Margol L, Sokolov Y, Sarsoza F, Head E, Hall J, Glabe C (2009) Annular protofibrils are a structurally and functionally distinct type of amyloid oligomer. $J$ Biol Chem 284, 4230-4237.

[62] Alarcon JM, Brito JA, Hermosilla T, Atwater I, Mears D, Rojas E (2006) Ion channel formation by Alzheimer's disease amyloid beta-peptide (Abeta40) in unilamellar liposomes is determined by anionic phospholipids. Peptides 27, 95-104.

[63] Inoue S (2008) In situ Abeta pores in AD brain are cylindrical assembly of Abeta protofilaments. Amyloid 15, 223-233.

[64] Yoshiike Y, Kayed R, Milton SC, Takashima A, Glabe CG (2007) Pore-forming proteins share structural and functional homology with amyloid oligomers. Neuromolecular Med $\mathbf{9}$, 270-275.

[65] Mandel SA, Amit T, Weinreb O, Youdim MB (2011) Understanding the broad-spectrum neuroprotective action profile of green tea polyphenols in aging and neurodegenerative diseases. J Alzheimers Dis 25, 187-208.

[66] Ono K, Yoshiike Y, Takashima A, Hasegawa K, Naiki H, Yamada M (2003) Potent anti-amyloidogenic and fibrildestabilizing effects of polyphenols in vitro: Implications for the prevention and therapeutics of Alzheimer's disease. J Neurochem $\mathbf{8 7}, 172-181$.

[67] Ono K, Hasegawa K, Naiki H, Yamada M (2004) Antiamyloidogenic activity of tannic acid and its activity to destabilize Alzheimer's beta-amyloid fibrils in vitro. Biochim Biophys Acta 1690, 193-202.

[68] Porat Y, Abramowitz A, Gazit E (2006) Inhibition of amyloid fibril formation by polyphenols: Structural similarity and aromatic interactions as a common inhibition mechanism. Chem Biol Drug Des 67, 27-37.

[69] Re F, Airoldi C, Zona C, Masserini M, La Ferla B, Quattrocchi N, Nicotra F (2010) Beta amyloid aggregation inhibitors: Small molecules as candidate drugs for therapy of Alzheimer's disease. Curr Med Chem 17, 2990-3006.

[70] Reza AA, Ladiwala AR, Dordick JS, Tessier PM (2011) Aromatic small molecules remodel toxic soluble oligomers of amyloid beta through three independent pathways. $J$ Biol Chem 286, 3209-3218.

[71] Bertsch U, Winklhofer KF, Hirschberger T, Bieschke J, Weber P, Hartl FU, Tavan P, Tatzelt J, Kretzschmar HA, Giese A (2005) Systematic identification of antiprion drugs by high-throughput screening based on scanning for intensely fluorescent targets. J Virol 79, 7785-7791.

[72] Schiffer NW, Broadley SA, Hirschberger T, Tavan P, Kretzschmar HA, Giese A, Haass C, Hartl FU, Schmid B (2007) Identification of anti-prion compounds as efficient inhibitors of polyglutamine protein aggregation in a zebrafish model. $J$ Biol Chem 282, 9195-9203.

[73] Hillmer AS, Putcha P, Levin J, Hogen T, Hyman BT, Kretzschmar H, McLean PJ, Giese A (2010) Converse modulation of toxic alpha-synuclein oligomers in living cells by N'-benzylidene-benzohydrazide derivates and ferric iron. Biochem Biophys Res Commun 391, 461-466.

[74] Newman DJ, Cragg GM (2009) Natural product scaffolds as leads to drugs. Future Med Chem 1, 1415-1427. 
Copyright of Journal of Alzheimer's Disease is the property of IOS Press and its content may not be copied or emailed to multiple sites or posted to a listserv without the copyright holder's express written permission.

However, users may print, download, or email articles for individual use. 
Copyright of Journal of Alzheimer's Disease is the property of IOS Press and its content may not be copied or emailed to multiple sites or posted to a listserv without the copyright holder's express written permission. However, users may print, download, or email articles for individual use. 